\title{
Notas e descrições em Disteniinae (Coleoptera, Cerambycidae)
}

\author{
Antonio Santos-Silva ${ }^{1} \&$ Ubirajara R. Martins ${ }^{1,2}$ \\ ${ }^{1}$ Museu de Zoologia, Universidade de São Paulo. Caixa Postal 42494, 04218-970 São Paulo, São Paulo, Brasil. \\ 2 Pesquisador do CNPq.
}

\begin{abstract}
Notes and descriptions on Disteniinae (Coleoptera, Cerambycidae). The American genera of Disteniinae Thomson, 1860 are alocated in tribes. Dynamostini Lacordaire, 1869, known only of the Oriental fauna, is recorded for the Neotropical Region. New synonymies established: Paracometes Villiers, $1959=$ Cometes Lepeletier \& Audinet-Serville, 1828; Cometes scapularis Bates, 1870 = Pseudocometes argutulus (Buquet, 1851); Cometes emarginata Fisher, 1946 = Distenia chrysostigma Bates, 1872. New species described: Cometes melzeri from Brazil (Minas Gerais and Paraná); C. wappesi from Panama (Chiriqui).

KEY WORDS. Aiurasyma, Cometes, Pseudocometes, taxonomy.
\end{abstract}

RESUMO. Os gêneros americanos de Disteniinae Thomson, 1860 são alocados em tribos. Dynamostini Lacordaire, 1869, conhecida somente da fauna Oriental, é registrada para a Região Neotropical. Novas sinonímias estabelecidas: Paracometes Villiers, 1959 = Cometes Lepeletier \& Audinet-Serville, 1828; Cometes scapularis Bates, $1870=$ Pseudocometes argutulus (Buquet, 1851); Cometes emarginata Fisher, 1946 = Distenia chrysostigma Bates, 1872. Novas espécies descritas: Cometes melzeri do Brasil (Minas Gerais e Paraná); C. wappesi do Panamá (Chiriqui).

PALAVRAS CHAVES. Aiurasyma, Cometes, Pseudocometes, taxonomia.

Após Villiers (1957, 1958a, b, 1959) não foram feitos estudos revisivos dos Disteniinae americanos. Duffy (1960) publicou algumas informações sobre a larva de Distenia rugiscapis Bates, 1885, Hüdepohl (1989) e Martins \& Galileo $(1994,2001)$ descreveram novos táxons.

Neste trabalho efetuamos algumas correções e sinonímias, alocamos Aiurasyma Martins \& Galileo, 2001, em tribo e descrevemos duas novas espécies em Cometes Lepeletier \& Audinet-Serville, 1828.

As siglas utilizadas ao longo do texto correspondem às seguintes instituições: ACMB, American Coleoptera Museum, Bulverde, Texas; FTHC, Frank T. Hovore Collection, Santa Clarita, Califórnia; MNHN, Muséum National d'Histoire Naturelle, Paris; MNRJ, Museu Nacional, Universidade Federal do Rio de Janeiro, Rio de Janeiro; MZSP, Museu de Zoologia, Universidade de São Paulo, São Paulo; USNM, National Museum of Natural History, Washington, D. C.

Chave para as tribos americanas de Disteniinae

1. Cavidades coxais anteriores fechadas; antenas dos machos atingem, no máximo, o ápice elitral .

Dynamostini Lacordaire, 1869

$1^{\prime}$. Cavidades coxais anteriores abertas; antenas dos machos, em geral, ultrapassam o ápice elitral .. 2

2. Artículo IV dos palpos maxilares dos machos longo e com apêndice (Fig. 1); nas fêmeas, curto, securiforme e sem apêndice Heteropalpini Villiers, 1962

2'. Artículo IV dos palpos maxilares dos machos curto (Fig. 2) e sem apêndices; nas fêmeas, curto, fusiforme e sem apêndices . Disteniini Thomson, 1860

\section{Dynamostini Lacordaire, 1869}

Dynamostides Lacordaire, 1869: 196.

Dynamostini; Gressitt, 1940: 27; Villiers, 1980: 33.

Gênero americano incluído: Aiurasyma Martins \& Galileo, 2001.

Dynamostini era conhecida somente da Região Oriental e contava com apenas uma espécie: Dynamostes audax Pascoe, 1857. Caracteriza-se pelos palpos maxilares dos machos sem apêndices, antenas curtas que não ultrapassam o ápice dos élitros, protórax sem tubérculos laterais e cavidades coxais anteriores fechadas.

Martins \& Galileo (2001) ao erigirem o gênero Aiurasyma não o alocaram em tribo. Aiurasyma é semelhante a Dynamostes, mas difere pelas antenas dos machos tão longas quanto o corpo, metafêmures mais lineares, subiguais em comprimento aos pro- e mesofêmures e tíbias inermes. Os machos de Dynamostes têm antenas que atingem, no máximo, o meio dos élitros, os metafêmures são notavelmente engrossados e mais longos que os demais e as tíbias são espinhosas.

Revista Brasileira de Zoologia 21 (1): 145-152, março 2004 


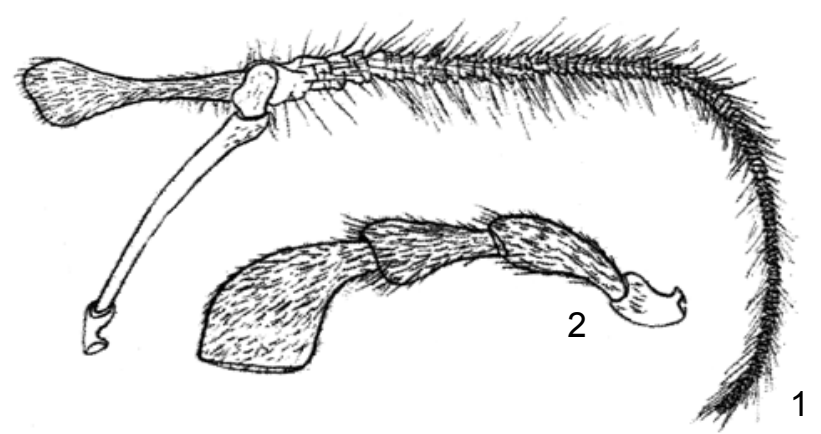

Figuras. 1-2. Palpo maxilar, macho (VILLIeRS 1980): (1) Pseudocometes sp.; (2) Cometes hirticornis.

\section{Heteropalpini Villiers, 1962}

Heteropalpini Villiers, 1962: 384; 1980: 33; Monné \& Giesbert, 1994: 303 (cat.).

Gêneros incluídos. Heteropalpus Buquet, 1840; Pseudocometes Villiers, 1957.

Pseudocometes difere de Heteropalpus principalmente pelos palpos maxilares dos machos. Em Pseudocometes, o ápice do quarto artículo é securiforme e seu apêndice tem mais do dobro de seu comprimento. Em Heteropalpus, o ápice do quarto artículo é fracamente claviforme e seu apêndice é pouco mais longo que seu comprimento. As demais diferenças apontadas por VILLIERS (1958a) são inconsistentes e de caráter específico e não genérico e, em alguns casos, equivocadas. Viluiers (1958a) ao descrever os olhos de Pseudocometes, escreveu: "Yeux gros, surtout chez les ơoù ils sont très rapprochés sur le vertex". Em contraposição, escreveu sobre Heteropalpus: "Yeux assez gros, mais assez écartés en dessus dans les deux sexes". No entanto, o exame de P. argutulus (Buquet, 1851) e de $H$. pretiosus Buquet, 1843, ambas espécies-tipo, mostra exatamente a mesma distância interocular.

Viluiers (1962) alocou Pseudocometes em Heteropalpini, tratando-o equivocadamente como Paracometes: "Paracometes basalis Villiers (sic)" (na verdade, Pseudocometes basalis Villiers, 1958). Villiers (1980) manteve o equivoco: "Dans le genre néotropical Paracometes Viluiers (Heteropalpini), le deuxième article des palpes maxillaires des mâles est très grêle et fortement renflé à l'apex; quatrième article un peu plus court que le deuxième, formant avec lui un angle droit, très étroit à la base, élargi à l'apex, constituant une sorte de cornet dont la face externe est sclérifiée et longuement pubescent et la face interne membraneuse, portant un dense revêtement de soies courtes; ce quatrième article porte à sa base en opposition avec lui un appendice membraneux subcylindrique, annelé, acuminé à l'apex, longuement pubescent, environ quatre fois plus long que le quatrième article (fig. 31 et 32 ). Chez les femelles, le quatrième article est fusiforme avec une aire sensorielle apicale petite (fig. 33)". As figuras a que VilLIERs (1980) se referiu, são de uma espécie de Pseudocometes, mas na explicação das figuras (l. c.: 15), foram tratadas como pertencentes a Paracometes acutipennis (Buquet, 1851), espécie-tipo desse último gênero.

\section{Pseudocometes argutulus (Buquet, 1851) \\ Figs 7-8}

Cometes argutulus Buquet, 1851: 190, pl. 5, fig. 4; Lacordaire, 1869: 230 (nota); Gemminger \& Harold, 1872: 2986 (cat.); Aurivillius, 1912: 11 (cat.); Boppe, 1921: 9.

Cometes scapularis Bates, 1870: 441; Gemminger \& Harold, 1872: 2986 (cat.); Aurivillius, 1912: 11 (cat.); Boppe, 1921: 9; Blackwelder, 1946: 558 (cat.). Syn. nov.

Cometes argutula; Blackwelder, 1946: 558 (cat.).

Pseudocometes argutulus; Villiers, 1957: 413 (nota); Villiers, 1958a: 38; Monné \& Giesbert, 1994: 303 (cat.).

Paracometes scapularis; Villiers, 1957: 413 (nota); 1958b: 55; Monné \& Giesbert, 1994: 303 (cat.).

Tipos, localidade-tipos. Cometes argutulus, proveniente da Guiana Francesa (Caiena), sexo e quantidade de espécimes não especificados, depositado(s) no MNHN, relacionado(s) por THomson (1878) como presente(s) em sua coleção.

Cometes scapularis, proveniente do Brasil (Amazonas, Tefé), holótipo fêmea, depositado no MNHN.

Tavakilian (comunicação pessoal) examinou os holótipos de C. argutulus Buquet, 1851 e C. scapularis Bates 1870, concluindo que são coespecíficos. F.T. Hovore (comunicação pessoal) baseado no exame de espécimes depositados na sua coleção e nas fotografias dos tipos chegou à mesma conclusão. Concordamos com os dois entomologistas citados acima, baseados no exame de espécimes depositados no MZSP e fotografias dos tipos, feitas por J. S. Moure e F. T. Hovore.

Villiers (1957) estabeleceu como espécie-tipo de Pseudocometes, Cometes argutulus (Figs. 7-8). VIlliers (1958a) ao invés de citar só holótipo ou síntipos, registrou sobre $C$. argutulus: "holotype + , allotype $\sigma^{\top}$, o que é incompreensível. Pode-se inferir que se Buquet (l. c.) dispusesse de um macho com os palpos aberrantes teria chamado atenção para esse caráter, uma vez que já havia descrito Heteropalpus pretiosus Buquet, 1840.

\section{Disteniini Thomson, 1860}

Disteniitae Thomson, 1860: 181; 1864: 225.

Disteniini Gressitt, 1940: 28; Gressitt, 1941: 332; 1951: 45; Löding, 1945: 113; Knull, 1946: 150; Bosq, 1947: 11; Zajciw, 1965: 12; 1972: 48 (cat.); 1974: 42 (cat.); Villiers, 1980: 33; Hayashi et al., 1988: 166; Monné \& Giesbert, 1994: 301 (cat., parte); Yanega, 1996: 25; Makihara et al., 2002: 190.

Gêneros americanos incluídos: Distenia Lepeletier \& Audinet-Serville, 1828; Cometes Lepeletier \& Audinet-Serville, 1828; Villiersicometes Santos-Silva, 2003. 


\section{Chave para os gêneros de Disteniini americanos}

1. Antenômeros uniformemente afilados em direção ao ápice; ápice dos fêmures freqüentemente espinhosos; élitros, em geral monocromáticos, ou com desenho de faixas longitudinais nas laterais

Distenia Lepeletier \& Audinet-Serville, 1828

$1^{\prime}$. Antenômeros subiguais em espessura ou antenômeros VVIII mais grossos do que III-IV e IX-XII; ápice dos fêmures raramente com espinhos (se presentes, curtos); élitros freqüentemente com desenhos de faixas transversais .... 2

2. Comprimento de, no máximo, $6 \mathrm{~mm}$; antenômeros V-VIII notavelmente espessados, principalmente em relação ao antenômero III Villiersicometes Santos-Silva, 2003

2'. Comprimento de, no mínimo, $8 \mathrm{~mm}$; antenômeros V-VIII não-notavelmente espessados

Cometes Audinet-Serville, 1828

\section{Cometes Lepeletier \& Audinet-Serville, 1828}

Cometes Lepeletier \& Audinet-Serville, 1828: 446; AudinetServille, 1835: 208; Laporte, 1840: 498; Blanchard, 1845: 163; Thomson, 1860: 183; 1864: 227; Lacordaire, 1869: 229; Bates, 1870: 440; 1880: 37; 1885: 275; Aurivillius, 1912: 11 (cat.); Boppe, 1921: 8; Blackwelder, 1946: 558 (cat.); Villiers, 1957: 408; Zajciw, 1965: 13; Monné \& Giesbert, 1994: 301 (cat.).

Paracometes Villiers, 1957: 412; 1958b: 43; Zajciw, 1965: 13; Chemsak \& Linsley, 1982: 116 (cat.); Chemsak et al., 1992: 163 (cat.); Monné \& Giesbert, 1994: 302 (cat.). Syn. nov.

Villiers (1957) dividiu o gênero Cometes em: Cometes $s$. str., Pseudocometes, Paracometes e Microcometes (atualmente Villiersicometes Santos-Silva, 2003). Villiersicometes apresenta dois caracteres distintivos constantes, que permitem distinguílo de Paracometes e Cometes: comprimento de, no máximo, 6 mm e notável espessamento dos antenômeros V-VIII.

Os caracteres utilizados por VILLIERs $(l . c$.) para separar Cometes e Paracometes, tanto na chave como nas descrições, são em sua maioria, pouco consistentes e variáveis. Paracometes, de acordo com Villiers (l.c.), diferencia-se de Cometes pela pontuação da cabeça e do pronoto "plus ou moins forte, les points jamais contigus" e "Élytres convexes". Cometes apresenta a pontuação da cabeça e do pronoto "très grossière, très dense, les points subcontigus" e "Élytres déprimés".

Cometes zikani Melzer, 1929, considerada em "incertae sedis" por VilLIERs $(l . c$.), que provavelmente não a conheceu, mostra caracteres dos dois gêneros: pontuação ainda mais fina e cerrada que Cometes hirticornis Lepeletier \& A.-Serville, 1825 (espécie-tipo do gênero), mas élitros convexos como nas espécies de Paracometes. Vale ressaltar, que as espécies alocadas em Paracometes não apresentam os élitros notavelmente convexos como afirmou Villiers (l. c.), mas, subplanos no disco. Villiers ( $l$. c.) escreveu ainda, na redescrição de Cometes: "Pronotum déprimé, transverse, portant une bosse latérale subconique". Em contraposição, na descrição de Paracometes, escreveu: "Pronotum fortement étranglé en avant et en arrière, ses rebords collaire et basilaire généralement striés en travers..., ses côtés avec une protubérance conique". C. zikani possui as saliências laterais do pronoto nitidamente aguçadas, como nas espécies de Paracometes e em C. hirticornis são variáveis. O espessamento dos antenômeros V-VIII é subigual nos dois gêneros, diferentemente do que afirmou Villiers (l. c.), embora seja pouco evidente em algumas espécies de Paracometes. Comparando-se as pernas de espécies alocadas nos dois gêneros, não se percebe a diferença no comprimento, comentada por Villiers ( $l$. c c.) e, tão pouco, os metafêmures são diferentes nos dois gêneros, observando-se, na verdade, variação entre espécies, principalmente em Paracometes.

Pelo exposto, julgamos inconsistente a manutenção de Paracometes e propomos sua transferência para a sinonímia de Cometes.

Espécies incluídas: Cometes acutipennis Buquet, 1851; C. amabilis (Martins \& Galileo, 2001) comb. nov.; C. amethystinus Villiers, 1957; C. apicalis Waterhouse, 1880; C. argodi Belon, 1896; C. bicolor Fisher, 1946; C. biplagiatus (Villiers, 1958) comb. nov.; C. carinatus Villiers, 1957; C. columbianus (Villiers, 1958) comb. nov.; C. cuneatus (Villiers, 1958) comb. nov.; C. ericae (Martins \& Galileo, 1994) comb. nov.; C. eximius Bates, 1885; C. festivus Bates, 1885; C. flavipennis Buquet, 1851; C. flavipes (Villirs, 1958) comb. nov.; C. flavoviridis (Villiers, 1958) comb. nov.; C. hilaris Bates, 1885; C. hirticornis Lepeletier \& AudinetServille, 1828; C. humeralis Villiers, 1957; C. laetificus Bates, 1870; C. mathani (Villiers, 1958); C. melzeri sp. nov.; C. peruvianus (Villiers, 1958) comb. nov.; C. pojuca (Martins \& Galileo, 2001) comb. nov.; C. pulcherrimus Bates, 1872 comb. nov.; C. quadrimaculatus (Villiers, 1958) comb. nov.; C. soledari Martins \& Galileo, 2001; C. spinipennis (Villiers, 1958) comb. nov.; C. tumidicollis (Villiers, 1958) comb. nov.; C. venustus Bates, 1885; C. violaceicollis (Villiers, 1958) comb. nov.; C. wappesi sp. nov.; C. zikani Melzer, 1926.

\section{Cometes zikani Melzer 1926 Fig. 3}

Cometes zikani Melzer, 1926: 6; Blackwelder, 1946: 558 (cat.); Zikán \& Wygodzinsky, 1948: 32; Villiers, 1957: 413 ("incertae sedis"); Monné \& Giesbert, 1994: 301 (cat.).

Cometes zikani Melzer, 1926 (Fig. 3) pertence ao gênero Cometes "sensu" Villiers, pela pontuação da cabeça, do pronoto e dos élitros, mas apresenta alguns caracteres que a colocam entre Cometes e Paracometes: élitros subconvexos; projeções laterais do pronoto salientes e aguçadas; metafêmures mais longos que os pro- e mesofêmures.

A série sintípica é composta por seis fêmeas (sete, de acordo com a descrição original), todas atualmente depositadas no MZSP. Melzer (l. c.) comentou sobre um dos síntipos: "A coloração não é constante. Assim falta, por exemplo, no exemplar menor a estria amarella na cabeça, enquanto os elytros na sua metade basal são completamente amarellos com excepção de

Revista Brasileira de Zoologia 21 (1): 145-152, março 2004 
uma pequena mancha alongada de cada lado do escutello o qual apresenta a mesma coloração como o resto dos elytros". O exame da série sintípica permite concluir que esse espécime pertence a uma espécie distinta, descrita neste trabalho: $C$. melzeri sp. nov. (Fig. 5)

Devido à exclusão de um dos exemplares da série sintípica, designamos lectótipo e paralectótipos. O lectótipo possui as seguintes etiquetas: (vermelha, impressa) Typus; (branca, impressa) J. Zikán; (branca, impressa, exceto a data que é manuscrita) Virginia, S. Minas Ger., Faz. Campos, 1500 m, 3.XII.1915; (branca, manuscrita) Cometes zikani Melzer; (branca, manuscrita) Typus.

Os paralectótipos portam as seguintes etiquetas:

1). (vermelha; impressa) - Cotypus; (branca) - (frente, impressa) - Virginia, S. Minas Ger., Faz. Campos, 1500 m - (verso, manuscrito) 21-XI-19; (branca, manuscrita) cotypus; (branca, impressa) IEEA; (branca, impressa) J. Zikán; (branca, manuscrita) Cometes zikani Melzer; (branca, datilografada) Mfot., II.71;

2). (vermelha, impressa) Cotypus; (branca, impressa) J. F. Zikán; (branca, impressa, exceto a data que é manuscrita, tanto na frente como no verso) Minas (Brazil), Passa Quatro, Faz. dos Campos, 23.XI.15 (frente), 23.XI.1915 (verso); (branca, manuscrita) Cotypus; (branca, manuscrita) Cometes zikani Melzer;

3). (vermelha, impressa) Cotypus; (branca, impressa) J. F. Zikán; (branca, impressa, exceto a data e o nome Zikán, que são manuscritos, tanto na frente como no verso) Minas (Brazil), Passa Quatro, Faz. dos Campos, XII.17 (frente), 25.XII.1917 Zikán (verso); (branca, manuscrita) Cotypus; (branca, manuscrita) Cometes zikani Melzer;

4). (vermelha, impressa) Cotypus; (branca, impressa) Z. F. Zikán; (branca, impressa, exceto a data que é manuscrita, tanto na frente como no verso) Minas (Brazil), Passa Quatro, Faz. dos Campos, 23.XI.15 (frente), 23.XI.19 (verso); (branca, manuscrita) Cotypus; (branca, manuscrita) Cometes zikani Melzer.

5) Holótipo de Cometes melzeri sp. nov.: (vermelha, impressa) Cotypus; (branca, impressa) Z. F. Zikán; (branca, manuscrita) 4.1.25, Mar.; (branca, manuscrita) Cotypus; (branca, manuscrita) Cometes zikani Melzer.

ZiKÁN \& WYgodZinsKY (1948) arrolaram os seguintes dados para a série típica de C. zikani: "Fazenda dos Campos, 1500 m, Virginia, Est. de Minas Gerais, Brasil, 3-12-1915, J. F. Zikán col., TYPUS, 1 ex., COTYPUS, 4 ex. Itatiaia, 1100 m, Est. do Rio de Janeiro, Brasil, 4-1-1925, J. F. Zikán col, COTYPUS, 1 ex.". Melzer (l. c.) disse: "Hab.: Passa Quatro, Sul de Minas. J. F. Zikán leg.". Assim, são contraditórios os dados apontados por ZiKáN \& Wygodzinsky (l.c.) e Melzer (l. c.) com aqueles que realmente estão nas etiquetas da série típica.

A descrição original dessa espécie (excetuando-se o exemplar de C. melzeri sp. nov., facilmente distinguível pelo desenho elitral), acrescida da fotografia aqui inserida (Fig. 3) permitem identificar a espécie.

\section{Cometes melzeri sp. nov.}

Figs 4-5

Etimologia. Espécie dedicada a Julius Melzer, entomologista que muito contribuiu para o conhecimento dos Cerambycidae.

Macho (Fig. 4). Face dorsal da cabeça suavemente convexa, preta, com manchas amareladas próximas e entre os tubérculos anteníferos, no clípeo e no labro; pontuação muito densa e grossa, exceto entre os tubérculos anteníferos, onde é sublisa e brilhante; pilosidade curta, esparsa e decumbente. Região posterior dos olhos com pontos mais esparsos do que na face dorsal da cabeça; pilosidade muito curta e dispersa, exceto próximo à margem ocular, onde há pêlos mais longos e concentrados. Face ventral da cabeça castanha nos dois terços anteriores, castanha-escura com um desenho triangular central, amarelado, no terço posterior. Gula lisa e brilhante, exceto alguns pontos esparsos próximos aos olhos; metade anterior intumescida, com pêlos esparsos, eretos e longos; metade posterior glabra. Mento amarelado, separado da gula por sulco transversal profundo. Gena com manchas irregulares amareladas; ápice arredondado; pilosidade curta, esparsa e decumbente. Distância entre os lobos oculares superiores maior do que o quádruplo da largura de um lobo. Clípeo convexo, com a borda anterior reta; pontuação grossa na área central, fina na base e ausente na área centro-apical; pilosidade esparsa e relativamente longa. Labro subplano no disco, com as bordas elevadas; escultura e pilosidade semelhantes às do clípeo. Último segmento dos palpos maxilares e labiais truncado no ápice. Antenas aproximadamente um terço mais longas do que o corpo. Escapo um quarto mais longo que o antenômero III, fortemente engrossado para o ápice; pontuação abundante e anastomosada na metade basal, mais fina e esparsa em direção ao ápice; pilosidade curta e decumbente. Antenômeros seguintes gradualmente mais curtos.

Protórax subquadrado, preto no pronoto, castanho escuro na face ventral e com três faixas amareladas: uma na margem anterior que circunda todo o segmento torácico, estreita no centro do pronoto e alargada em direção à face ventral; outras duas, dorsais, nas laterais da margem posterior. Partes laterais do protórax com saliência de ápice aguçado. Prosterno com pontos e pêlos muito esparsos. Ápice do processo prosternal afilado. Mesosterno com pilosidade relativamente longa e abundante. Metasterno castanho-escuro com pontos grossos e abundantes nas laterais, menores e mais esparsos em direção ao centro do disco; pilosidade com o mesmo padrão de distribuição da pontuação.

Élitros amarelados na metade anterior e pretos na metade apical; manchas castanho-escuras, subelípticas, uma de cada lado do escutelo e uma faixa castanho-escura ao longo da epipleura, que se inicia no úmero e termina na metade apical; pontuação grossa, cerrada e profunda na metade anterior, anastomosada na metade posterior; três costas que iniciam na 

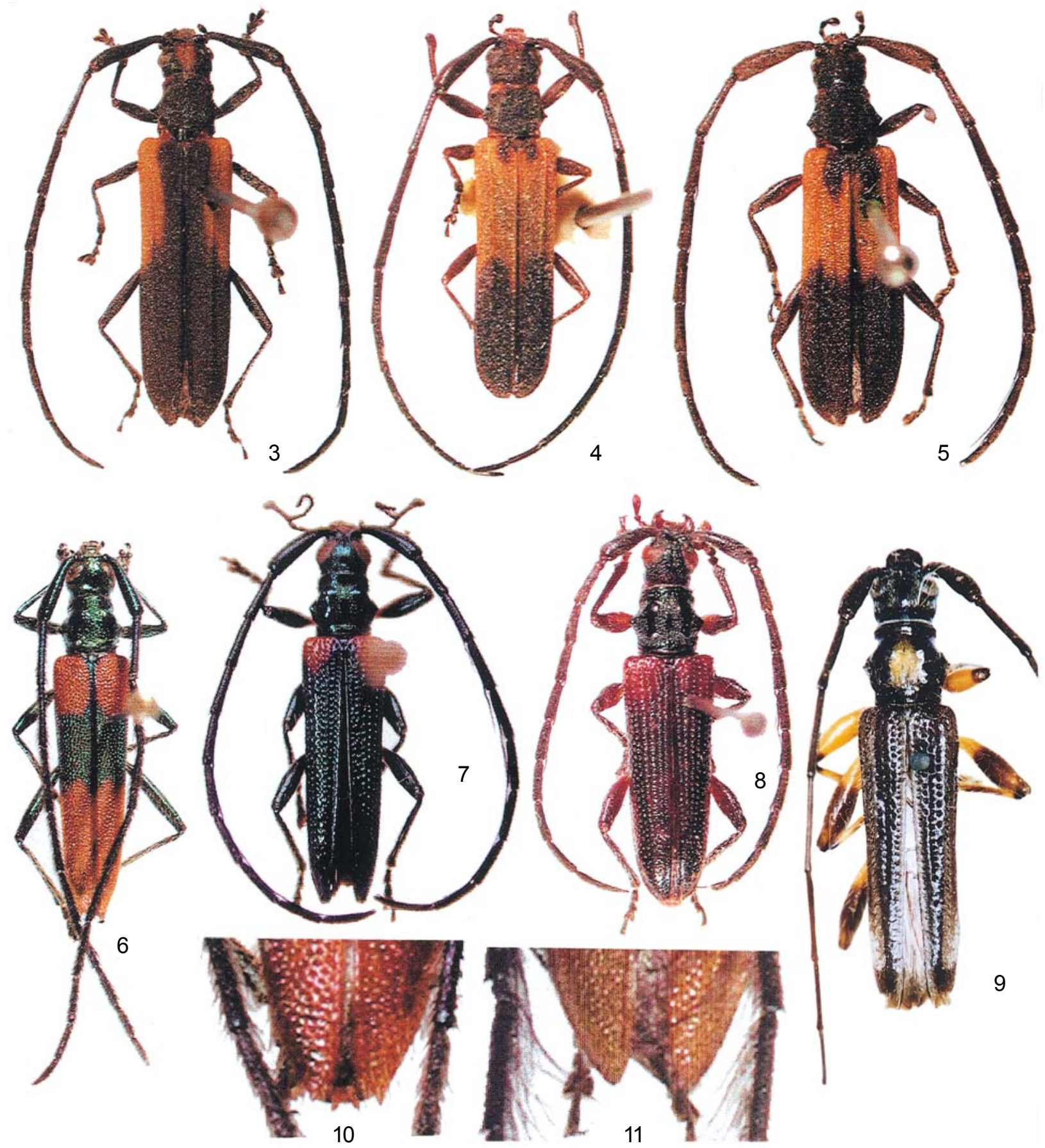

Figuras 3-11. (3) Cometes zikani, 14,4 mm; (4-5) Cometes melzeri sp. nov., vista dorsal: (4) parátipo macho, 9,2 mm; (5) holótipo fêmea, 11,4 mm; $(6,10)$ Cometes wappesi sp. nov., holótipo macho,10,0 mm: (6) vista dorsal; (10) ápice elitral; (7-8) Pseudocometes argutulus, vista dorsal: (7) macho, 14,1 mm (fotografado por F. T. Hovore); (8) fêmea, 13,8 mm; (9) Distenia chrysostigma, 7,7 mm; (11) Cometes festivus, ápice elitral. 
região basal: a primeira, mais interna, pouco conspícua, atinge apenas a metade do élitro; a segunda, bem marcada, inicia-se próximo ao úmero e termina no terço apical; a última mais externa, mais forte que as outras, inicia-se no úmero e termina no quarto apical; pilosidade curta e decumbente no disco e mais longa, cerrada e cerdosa nas bordas; ápice elitral arredondado. Urosternitos castanho-escuros com pontos e pêlos mais abundantes nas laterais do que no centro. Pernas castanhoescuras, pilosas, com as coxas e a base dos fêmures amareladas; pernas posteriores mais longas do que as demais.

Fêmea (Fig. 5). Antenas aproximadamente um quarto mais longas que o corpo; antenômeros III-XI mais grossos; ápice do último segmento dos palpos maxilares e labiais aguçado; coxas e parte basal dos fêmures, apenas mais claras do que o restante das pernas.

Dimensões em milímetros (macho/fêmea). Comprimento total, 9,2-10,5/11,4-11,8; comprimento do protórax no centro, 1,3-1,5/1,7-1,8; largura do protórax entre os ápices das saliências laterais, 1,6-1,8/2,2-2,4; largura do protórax na frente, 1,31,5/1,6-1,7; largura do protórax atrás, 1,3-1,5/1,8-1,8; largura umeral, 2,0-2,2/2,6-2,8; comprimento dos élitros 6,4-6,5/7,9-8,1.

Material-tipo. Holótipo fêmea (paralectótipo de C. zikani Melzer) proveniente do Brasil, Minas Gerais: Mar de Espanha, 4.I.1925, J. F. Zikán leg. (MZSP). Parátipos: BRASIL, Rio de Janeiro: Itatiaia (900 m), macho, 1.XI.1947, H. Zellibor leg. (MNRJ). São Paulo: São Paulo (Cantareira), fêmea, 1.XII.1951, H. Zellibor leg. (MNRJ). Santa Catarina: Seara (Nova Teutônia, 300-500 m), macho, 4.X.1976, F. Plaumann leg. (MZSP).

Discussão. C. melzeri é semelhante à C. zikani pela coloração geral e desenho elitral. Difere: corpo mais curto (élitros com aproximadamente quatro vezes o comprimento do protórax); cabeça com mancha amarelada reduzida; escapo mais curto e engrossado para o ápice; pontuação elitral mais grossa e esparsa na metade basal; desenho elitral (Figs. 4 - 5); costas elitrais mais destacadas; meso- e metafêmures mais claviformes. Em C. zikani o corpo é mais longo (élitros com aproximadamente cinco vezes o comprimento do protórax); cabeça com grande mancha amarelada entre os tubérculos anteníferos e o protórax; escapo mais longo e estreito para o ápice; pontuação elitral mais fina e anastomosada na metade basal; desenho elitral (Fig. 3); costas elitrais menos elevadas; meso- e metafêmures mais esguios.

\section{Cometes wappesi sp. nov.}

Figs 6, 10

Etimologia. Espécie dedicada a J. E. Wappes (ACMB).

Macho (Fig. 6). Tegumento verde-escuro metálico com reflexos violáceos em algumas áreas; desenho elitral alaranjado. Cabeça globulosa nos dois terços anteriores. Escultura dorsal da cabeça formada por pontos grossos e esparsos ao longo da sutura coronal, pouco mais densos em direção à área posterior dos olhos, sulcos oblíquos e curtos ao longo da sutura coronal (como nervuras de uma folha) e, sulcos longos circundando o ápice dessa mesma sutura; pilosidade longa e esparsa, mais densa em direção à área posterior dos olhos e área entre os olhos e a base das antenas (principalmente nesta última). Ápice das genas não-projetado, arredondado; pilosidade relativamente densa. Gula com pontos e pêlos esparsos, mais concentrados em direção às laterais. Mento elevado, separado da gula por sulco transversal. Último segmento dos palpos maxilares e labiais truncado. Distância entre os lobos oculares superiores aproximadamente cinco vezes a largura de um lobo. Clípeo convexo, pontuado e com pêlos longos nos três quintos basais; borda anterior reta. Labro liso e glabro no disco, com pontos e pêlos esparsos na base e escova de pêlos na borda anterior. Antenas um terço mais longas do que o corpo; escapo curvo na base, progressivamente engrossado para o ápice, com pontos grossos, esparsos e rasos, entremeados por finas estrias transversais e pilosidade dispersa. Antenômeros III-XI com pilosidade curta e densa nas regiões dorsal e lateral e longa na região ventral; antenômero III apenas mais curto que o escapo; antenômeros seguintes gradativamente mais curtos.

Protórax mais longo do que largo; parte anterior e posterior pouco destacada do restante do segmento e sulcada transversalmente (a anterior pouco mais estreita do que a posterior); partes laterais com saliência de ápice subarredondado. Pronoto com duas calosidades de cada lado (as anteriores maiores e mais lisas); disco deprimido com pontuação muito densa e anastomosada; área entre as saliências discais e as laterais com pontos grossos e esparsos; pilosidade relativamente longa e esparsa. Prosterno transversalmente sulcado, com pêlos pouco concentrados. Meso- e metasterno com pilosidade abundante.

Cada élitro com mancha alaranjada elíptica no terço basal que não atinge as epipleuras e a sutura e toda metade apical; pontuação densa e grossa; pilosidade curta e esparsa; ápice truncado, com o ângulo externo espinhoso (Fig. 10).

Urosternitos com pontos e pêlos mais concentrados nas laterais. Ápice do último urosternito suavemente côncavo. Pernas com pêlos esparsos, mais concentrados no ápice das tíbias.

Fêmea. Difere do macho na forma do ápice do último segmento dos palpos maxilares e labiais que são aguçados e na forma arredondada do ápice do último urosternito.

Dimensões em milímetros (macho/fêmea). Comprimento total, $10,0-13,5 / 10,0-14,5$; comprimento do protórax no centro, 1,7-2,0/1,5-2,2; largura do protórax entre os ápices das saliências laterais, 2,0-2,4/1,7-3,0; largura do protórax na frente, 1,21,3/1,2-2,0; largura do protórax atrás, 1,5-1,7/1,5-3,0; largura umeral, 2,2-2,6/2,0-3,2; comprimento dos élitros 7,5-9,3/7,5-10,5.

Material-tipo. Holótipo macho proveniente do Panamá, Chiriqui: $6 \mathrm{~km}$ N Fortuna ("Continental Divide Trail"), 27.V.1992, J.E. Wappes leg. (USNM). Parátipos: Panamá, Chiriqui: "Continental Divide Trail", 2 fêmeas, 12-14.V.1999, J.E. Wappes \& Morris leg. (MZSP e USNM); 10 km NE Represa Fortuna, 2 machos e 2 fêmeas, 23-26.V.1984, E.F. Giesbert leg. (FTHC); 2 machos e 1 fêmea, 2.VI.1986, F.T. Hovore leg. (FTHC); 2 ma- 
chos, 1-2.VI.1986, E.F. Giesbert leg. (FTHC); 7 km NE Represa Fortuna, 1 macho, 22-26.V.1984, E.F. Giesbert leg. (FTHC).

Discussão. Cometes wappesi é semelhante a Cometes festivus Bates, 1885. Difere: cabeça mais globulosa e com pontuação mais esparsa; pronoto deprimido no disco; áreas alaranjadas dos élitros maiores; ápice elitral (Fig. 10) truncado e espinhoso no canto externo. Em C. festivus, a cabeça é mais alongada e a pontuação mais densa; pronoto com calosidade na região central do disco; áreas alaranjadas dos élitros menores; ápice elitral (Fig. 11) arredondado e sem espinhos.

\section{Cometes pojuca (Martins \& Galileo, 2001) comb. nov.}

Paracometes pojuca Martins \& Galileo, 2001: 17.

Originalmente descrita do Brasil (Pará), registra-se pela primeira vez para o estado de Rondônia.

Material examinado. Brasil. Rondônia: Ariquemes $(62 \mathrm{~km}$ SW, Fazenda Rancho Grande), fêmea, 16.X.1993, C.W. \& L.B. O'Brien leg. (AMCM).

\section{Distenia chrysostigma Bates, 1872}

Fig. 9

Distenia chrysostigma Bates, 1872: 196; 1880: 36; Gemminger \& Harold, 1872: 2985 (cat.); Aurvillius, 1912: 8 (cat.); Boppe, 1921: 5; Blackwelder, 1946: 557 (cat.); Villiers, 1959: 56 (chave); Chemsak \& Linsley, 1982: 115 (cat.); Chemsak et al., 1992: 163 (cat.); Monné \& Giesbert, 1994: 301 (cat.); Maes et al., 1994: 26 (cat.).

Cometes emarginata Fisher, 1946: 331. Syn. nov.

Paracometes emarginata; Villiers, 1957: 412; 1958b: 56; Chemsak \& Linsley, 1982: 116 (cat.); Chemsak et al., 1992: 164 (cat.).

Paracometes emarginatus; Monné \& Giesbert, 1994: 303.

VILLIERs (1957: 407), na chave para os gêneros americanos de Disteniinae, separou Cometes "Yeux à facettes fines, fémurs plus ou moins claviformes" de Distenia "Yeux à facettes plus grossière, fémurs subcylindriques". No entanto, esses caracteres são variáveis nos dois gêneros. Espécies como Distenia hoegei Bates, 1885 e D. trifasciata Bates, 1892, apresentam os fêmures claviformes e Cometes soledari Martins \& Galileo, 2001 e C. argodi Belon, 1896, possuem os omatídios similares a várias espécies de Distenia. A alocação de algumas espécies é, de certa forma, problemática, dependendo dos caracteres utilizados. Provavelmente, essa foi a razão que levou Fisher (1946) a descrever C. emarginata em Cometes.

O exame do espécime relacionado abaixo, diapositivos do holótipo de Cometes emarginata (USNM), feitos por J.S. Moure e J. Wappes e a descrição original de Distenia chrysostigma Bates, 1872 (Fig. 9), permitem sinonimizar C. emarginata.

Material examinado. Costa Rica. Limón: Planície do Rio Reventazon (Fazenda Hamburg, na floresta, em folha de palmeira), macho, 25.VII.1925, F. Nevermann leg. (MZSP).

\section{AGRADECIMENTOS}

A J.E. Wappes (ACMB) e Dr. Miguel A. Monné (MNRJ) pelo empréstimo de material para estudo.

\section{REFERÊNCIAS BIBLIOGRÁFICAS}

Audinet-Serville, M. 1835. Nouvelle classification de la famille des longicornes. Annales de la Société entomologique de France, Paris, (1) 4: 197-228.

Auriviluius, C. 1912. Coleopterorum Catalogus, pars 39, Cerambycinae. Berlin, W. Junk, $574 \mathrm{p}$.

Bates, H.W. 1870. Contributions to an insect fauna of the Amazon Valley (Coleoptera: Cerambycidae). The Transactions of the Entomological Society of London, London, 1870: 391-444.

-1872. On the longicorn Coleoptera of Chontales, Nicaragua. The Transactions of the Entomological Society of London, London, 1872: 163-238.

1880. Coleoptera. In: F.D.C. Goldman \& O. SAlviN (Eds). Biologia Centrali-Americana, Insecta. London, British Museum (Natural History), v. 5, p. 17-152.

. 1885. Coleoptera. In: F.D.C. Goldman \& O. SALviN (Eds). Biologia Centrali-Americana, Insecta. London, British Museum (Natural History), v. 5, p. 249-436.

BlackWelder, R.E. 1946. Checklist of the coleopterous insects of Mexico, Central America, the West Indies and South America. Part 4. Bulletin of the United States National Museum, Washington, D.C., 185: 551-763.

BlanCHARD, É. 1845. Histoire des insectes, traitant de leurs moeurs et de leurs métamorphoses en général, et comprenant une nouvelle classification fondée sur leurs rapports naturels. Paris, 2: 1-524.

Boppe, P. 1921. Coleoptera, Longicornia, Fam. Cerambycidae, Subfam. Disteniinae Lepturinae. In: P. Wytsman (Ed.). Genera Insectorum. Bruxelles, v. 178, 121p.

Bose, J. M.1947. Catálogo preliminario de los Coleópteros del Paraguay. Parte III. Superfamilia Cerambycoidea. Revista de la Sociedad Cientifica del Paraguay, Asunción, 7 (2): 5-32.

Buquet, J. B. 1851. Notice monographique sur le genre Cometes, de la famille des Longicornes, tribu des Lepturètes. Revue et Magasin de Zoologie, Paris, (2) 3: 188-192.

Chemsak, J. A. \& E. G. Linsley. 1982. Checklist of Cerambycidae. The Longhorned beetles. Checklist of the Cerambycidae and Disteniidae of North America, Central America, and the West Indies (Coleoptera). Medford, Plexus, 138p.

Chemsak, J.A.; E.G. Linsley \& F.A. Noguera. 1992. Listados Faunisticos de México II. Los Cerambycidae y Disteniidae de Norteamerica, Centroamerica y las Indias Occidentales (Coleoptera). Universidad Nacional Autónoma de Mexico, Instituto de Biologia, México, 204p.

Duffy, E.A.J. 1960. A monograph of the immature stages of Neotropical timber beetles (Cerambycidae). London, British Museum (Natural History), VII+327p. 
FISHER, W.S. 1946. New cerambycid beetles belonging to the tribe Disteniini from Central and South America. Proceedings of the United States National Museum, Washington, D.C., 96 (3201): 329-333.

Gemminger, M. \& E. Harold. 1872. Catalogus Coleopterorum hucusque descriptorum synonymicus et systematicus. Monachii, 9: 2669-2988.

GressitT, J.L. 1940. The longicorn beetles of Hainan Island (Coleoptera: Cerambycidae). The Philippine Journal of Science, Manila, 72 (1-2): 1-239.

. 1941. A collection of longicorn beetles from Thai (Coleoptera: Cerambycidae). The Philippine Journal of Science, Manila, 74 (4): 331-345.

- 1951. Longicorn beetles of China. Longicornia, Paris, 2: 1-667.

Hayashi, M.; S. Nakamura; H. Makihara; A. Saito \& Y.-I Chu. 1988. A list of Cerambycid-beetles from Taiwan, (I). Subfamilies Disteniinae, Parandrinae, Prioninae, Philinae, Aseminae, Spondylinae \& Lepturinae. Chinese Journal of Entomology, Tao-Yuan, 8: 165-184.

HüDEPOHL, K.E. 1989. Nova espécie do gênero Distenia Mulsant (Coleoptera, Disteniidae). Revista Brasileira de Entomologia, São Paulo, 33 (2): 357-358.

KNULL, J. N. 1946. The long-horned beetles of Ohio. Bulletin of Ohio Biological Survey, Columbus, 39: 133-354.

LACORDAIRE, J.T. 1869. Histoire Naturelle des Insectes. Genera des Coléoptères, Paris, Librairie Encyclopedique de Roret, 8: $1-552$.

Laporte, F.L.N. 1840. Histoire Naturelle des Insectes Coléoptères. Paris, 2: 1-563.

Lepeletier, A.L.M. \& J.G. Audinet-Serville. 1828. Entomologie. In: P.A. LATreille (Ed.). Encyclopédie Méthodique, ou par ordre de matière, par un société de gens de letters, Paris, 10 (2): 345-832.

Löding, H. P. 1945. Catalogue of the Beetles of Alabama. Geological Survey of Alabama, Wetumpka, 11: 1-172.

Maes, J.M.; A. Allen; M.A. Monné \& F.T. Hovore, 1994. Catálogo de Los Cerambycidae (Coleoptera) de Nicaragua. Revista Nicaraguense de Entomologia, León, 27: 1-58.

Martins, U.R \& M.H.M. Galileo. 1994. Novas espécies e notas sobre Cerambycidae e Disteniidae (Coleoptera) do Estado de Tocantins, Brasil. Iheringia, Série Zoologia, Porto Alegre, (77): 77-82.

. 2001. Novos táxons de Disteniidae (Coleoptera) Neotropicais. Iheringia, Série Zoologia, Porto Alegre, (90): $15-20$.

Makihara, H.; W.A. Noerdjito \& Sugiarto. 2002. Longicorn beetles from Gunung Halimum National Park, West Java, Indonesia from 1997-2002 (Coleoptera, Disteniidae and Cerambycidae). Bulletin of the Forestry and Forest Products Research Institute, Ibaraki, 1 (3) (384): 189-223.

Melzer, J. 1926. Longicórneos (Col.) do Brasil, novos ou pouco conhecidos. Publicações do Museu Nacional, Rio de Ja- neiro, 7: 1-15.

Monné, M.A. \& E.F. Giesbert. 1994. Checklist of the Cerambycidae and Disteniidae (Coleoptera) of the Western Hemisphere. Burbank, Wolfsgarden Books, 410p.

Tномsоn, J. 1860. Essai d'une classification de la famille des cérambycides et matériaux pour servir a une monographie de cette famille. Paris, 404p.

- 1864. Systema cerambycidarum ou exposé de tous lês genres compris dans la famille dês cérambycides et familles limitrophes. Mémoires de la Société Royale des Sciences de Liège, Paris, 19: 1-540.

. 1878. Typi cerambycidarum Musei Thomsoniani. Paris, E. Deyrolle, 21p.

Villiers, A. 1957. Démembrement du genre Cometes Serville. Descriptions des Genres Pseudocometes, Paracometes, Microcometes nov. et de plusieurs espèces nouvelles. (Col. Cerambycidae Disteniinae). Bulletin du Muséum de Histoire Naturelle, $2^{\mathrm{a}}$ série, Paris, 29 (5): 407-413.

- 1958a. Révision des genres Pseudocometes Villiers et Heteropalpus Buquet (Co. Cerambycidae Disteniinae). Bulletin de la Société entomologique de France, Paris, 63: 37-40.

. 1958b. Révision du genre Paracometes Villiers (Col. Cerambycidae Disteniinae). Revue Française d'Entomologie, Paris, 35: 43-56.

. 1959. Essai sur les Distenia Américains (Col. Cerambycidae). Revue Française d'Entomologie, Paris, 26 (2): 55-76.

. 1962. Sur la structure des palpes maxillaires de quelques Disteniinae (Coleoptera Cerambycidae). In: XI International Congress of Entomology, Wien, 1: 382-385.

. 1980. Insectes Coléoptères, Cerambycidae, Disteniinae. Faune de Madagascar, Paris, 52: 1-134.

YANEGA, D. 1996. Field guide to northeastern longhorned beetles (Coleoptera: Cerambycidae). Champaign, Illinois Natural History Survey, $174 \mathrm{p}$.

ZajCIW, D. 1965. As fontes para a determinação dos longicórneos do Brasil (Coleoptera, Cerambycidae). Anuário brasileiro de Economia Florestal, Rio de Janeiro, 17: 3-41.

- 1972. Contribuição para o estudo da fauna dos longicórneos do Parque Nacional do Itatiaia. Brasil Florestal, Rio de Janeiro, 3: 40-72.

-1974. Contribuição para o estudo da fauna dos longicórneos das florestas do Estado do Espírito Santo e principalmente da Reserva Biológica "Soôretama". Boletim Técnico do Instituto Brasileiro de Desenvolvimento Florestal, Rio de Janeiro, 4: 37-91.

ZiKÁN, D. \& P. WygodZinsky, 1948. Catálogo dos tipos de insetos do Instituto de Ecologia e Experimentação Agrícolas. Boletim do Serviço de Pesquisas Agronômicas, Rio de Janeiro, 4: 1-93.

Recebido em 02.VII.2003; aceito em 04.III.2004. 